International Journal of Engineering \& Technology, $7(3.1)(2018) 86-89$
International Journal of Engineering \& Technology
SPC
Website: www.sciencepubco.com/index.php/IJET
Research paper

\title{
Smart Energy Meter for Computing Energy Cost Based on Consumers Category and Tariff Rates
}

\author{
Jaichandran $\mathbf{R}^{1 *}$, Rajaprakash $\mathbf{S}^{2}$, Amit Kumar Verma ${ }^{3}$, Abhishek Sinha ${ }^{4}$,Pankaj Kumar Singh ${ }^{5}$ \\ ${ }_{1,2,3,4,5}$ Centre of Excellence for IoT, Department of CSE, Aarupadai Veedu Institute of Technology, \\ Vinayaka Mission's Research Foundation (Deemed to be University), \\ Kanchipuram District,Tamil Nadu 603104, India. \\ *Corresponding author E-mail:rjaichandran@gmail.com
}

\begin{abstract}
This paper present a smart energy meter for computing energy cost based on consumers category and tariff rates. Proposed smart energy meter computes consumer energy cost, subsidy amount, and payable energy cost based on consumers category and tariff rates of Tamil Nadu electricity board. Prototype is experimented in various scenarios and evaluated using test cases. Results show the proposed smart energy meter is effective in computing energy cost based on consumers category and tariff rates.
\end{abstract}

Keywords: Energy cost; energy meter; internet of thing; smart energy meter; tamil nadu electricity board.

\section{Introduction}

Initially during the evolution of internet it was only computers that are connected to internet. Later mobile phones are connected via internet. Now with Internet of Things (IoT) any gadgets like watches, shirts, shoes, refrigerators, washing machine, etc., can be connected via internet [10]. Energy meters are connected with internet to monitor consumer's energy usage. Presently many Electricity Boards (EBs) manually collects energy meter readings and enters it in server for online access. Manual monitoring of energy meters consumes lot of time, human efforts, and may lead to complications.

In literature many IoT enabled energy meters are proposed. But most of them computed energy cost without considering consumers category and tariff rates [6] [7]. Here we proposed a smart energy meter for computing energy cost based on consumer's category and tariff rates. Consumer's category and tariff rates of Tamil Nadu Electricity Board (TNEB) are taken into consideration [11]. Proposed prototype is experimented using various scenarios and evaluated using energy units as test cases. Consumer's Energy Cost (CEC), Subsidy Amount (SA), and Payable Energy Cost (PEC) are computed for various consumer categories using test cases. Graph is plotted to compare energy cost paid by various consumer categories. Results show the prototype is effective in computing energy cost based on consumer's category and tariff rates.

\section{Literature Review}

In most of the EBs humans collects energy meter readings. A person visit every consumer's home or office periodically to collect information such as number of units consumed (NUC), period of consumption, and enters it in server for generating electricity bills. Existing system requires human involvement in col- lecting customer's energy meter readings. In literature, IoT based energy meter is proposed to collecting consumer's energy meter readings remotely without human involvement. Here we summarize few of them.

Rashmi M.N et al., (2016) developed "IOT based Energy Meter Monitoring using ARM Cortex M4 with Android Application". In this system ARM microcontroller and wifi module is used for connecting energy meter with central server. Advantage of this system is mobile app is used for monitoring daily and monthly usage of energy and payment of bills are made online.

Gopinath S et al., (2016) developed "Internet of Things (IOT) based Energy Meter". In this system PIC microcontroller is used for calculating energy consumption charges. Consumer's bill details are sent to central server using GSM module. Advantage of this system is voltage sensor and current sensor is used to monitor power fluctuation and theft.

Dinesh Prasanth M. K et al., (2015) developed a "Live Energy Meter Reading and Billing System through GPRS". In this system EB meter is connected to server using PIC microcontroller and GPRS module. Energy meter readings are periodically uploaded to server and monthly bills are generated online. Advantage of this system is that consumer's energy consumption details and bill amount are accessed online using mobile app and protected by user name and password.

Darshan Iyer n, et al., (2015) developed an "IoT Based Electricity Energy Meter Reading, Theft Detection and Disconnection using PLC modem and Power optimization". In this system energy meter is connected to server using PIC microcontroller and wifi module. IP address is used as key for establishing connection between serve and energy meter. If consumer not paid electricity bill within stipulated time period then commands are sent to disconnect energy supply.

Most of the existing IoT energy meter computes energy cost without considering consumers category and tariff rates [1][5] [8] [10]. But in real time, EBs have different category of consumers and varies tariff rates are fixed for each category of consumers. Therefore it is necessary to develop a smart energy meter for 
computing consumers energy cost based on consumers category and tariff rates.

\section{Methodology}

Figure 1 illustrates methodology for smart energy meter for computing consumers energy cost based on consumers category and tariff rates. Smart energy meter monitors energy consumed by a consumer and send to microcontroller for processing. Microcontroller computes energy cost of consumer by multiplying NUC with energy cost per unit based on the tariff rate of consumer Wireless module sends consumer data such as energy consumed detail and energy cost to EBs server. Let us consider the consumers category and tariff rates of TNEB. Table 1 shows the different categories of consumers classified by TNEB [10]. Table 1 classifies consumers into twelve categories and actual tariff rates fixed by TNEB for each category of consumers are given in table 2 [11]. Government provides subsidy to certain category of consumers such as domestic users, weavers, farmers etc. Details of subsidized consumers and their tariff rates are given in table 3 [11].

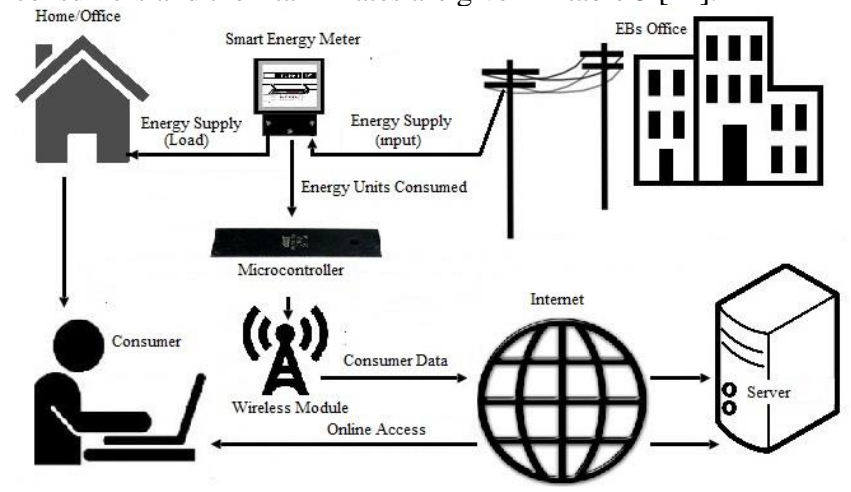

Fig. 1: Methodology

Table 1: Consumers category

\begin{tabular}{|c|l|}
\hline $\begin{array}{c}\text { Consumer } \\
\text { Category }\end{array}$ & \multicolumn{1}{|c|}{ Description } \\
\hline 1 & $\begin{array}{l}\text { Domestic, Old age homes, Handloom, } \\
\text { Consulting rooms, and Nutritious Meals Centers. }\end{array}$ \\
\hline 2 & $\begin{array}{l}\text { Residential Colonies of Defense, Railway, and Police quar- } \\
\text { ters }\end{array}$ \\
\hline 3 & $\begin{array}{l}\text { Public lighting by Govt./Local bodies, Public water supply, } \\
\text { Sewerage etc., }\end{array}$ \\
\hline 4 & $\begin{array}{l}\text { Govt. and Govt. aided Educational Institutions, Govt. Hospi- } \\
\text { tals and Research labs }\end{array}$ \\
\hline 5 & Private Educational Institutions \& Hostels \\
\hline 6 & Public worship places like Temple, Mosque, Church etc. \\
\hline 7 & $\begin{array}{l}\text { Cottage and Tiny Industries, Agricultural and } \\
\text { allied activities, Sericulture, Floriculture, Horticulture and } \\
\text { Fish/Prawn culture etc. }\end{array}$ \\
\hline 8 & Power Looms \\
\hline 9 & Industries, welding sets and IT \\
\hline 10 & $\begin{array}{l}\text { Agricultural, sericulture, floriculture, horticulture and } \\
\text { fish/prawn culture etc., }\end{array}$ \\
\hline 11 & Commercial \\
\hline 12 & $\begin{array}{l}\text { Temporary activities, construction of buildings and Lavish } \\
\text { illumination, additional construction }\end{array}$ \\
\hline
\end{tabular}

Table 2: Actual tariff rates

\begin{tabular}{|c|c|c|c|c|}
\hline \multicolumn{2}{|c|}{$\begin{array}{l}\text { Consumer } \\
\text { Category }\end{array}$} & NUC & $\begin{array}{c}\text { Actual Energy } \\
\text { Cost }\left(\mathrm{X}_{\mathrm{n}}\right) \\
(\mathrm{Rs} / \text { Unit })\end{array}$ & $\begin{array}{c}\text { Actual Fixed } \\
\text { Cost }\left(\mathrm{I}_{\mathrm{n}}\right) \\
\text { (Rs/2Months) }\end{array}$ \\
\hline \multirow{10}{*}{1} & \multirow{2}{*}{ A } & \multicolumn{3}{|c|}{$(\mathrm{NUC} \geq 0$ and $\mathrm{NUC} \leq 200)$} \\
\hline & & $0-200$ units & 2.50 & 30 \\
\hline & \multirow{3}{*}{ B } & & 201 and NUC & $00)$ \\
\hline & & $0-200$ units & 2.50 & \multirow{2}{*}{40} \\
\hline & & $201-500$ units & 3.00 & \\
\hline & \multirow{5}{*}{$\mathrm{C}$} & & $(\mathrm{NUC}>500)$ & \\
\hline & & $0-100$ units & 2.50 & \multirow{4}{*}{50} \\
\hline & & $101-200$ units & 3.50 & \\
\hline & & 201-500 units & 4.60 & \\
\hline & & $>500$ units & 6.60 & \\
\hline
\end{tabular}

\begin{tabular}{|c|c|c|c|c|}
\hline & 2 & \multirow{5}{*}{ For all units } & 4.60 & 120 \\
\hline & 3 & & 6.35 & 120 \\
\hline & 4 & & 5.75 & 120 \\
\hline & 5 & & 7.50 & 120 \\
\hline & 6 & & 5.75 & 120 \\
\hline \multirow{2}{*}{\multicolumn{2}{|c|}{7}} & $<500$ units & 4.00 & \multirow{2}{*}{40} \\
\hline & & $>500$ units & 4.60 & \\
\hline \multirow{5}{*}{8} & $\overline{\mathrm{A}}$ & $\leq 500$ units & 5.20 & \multirow{5}{*}{120} \\
\hline & B & $501-750$ units & \multirow{4}{*}{5.75} & \\
\hline & $\mathrm{C}$ & $751-1000$ units & & \\
\hline & $\mathrm{D}$ & $1001-1500$ units & & \\
\hline & E & $>1500$ units & & \\
\hline & 9 & \multirow{2}{*}{ For all units } & 6.35 & 70 \\
\hline & 10 & & 3.22 & 0 \\
\hline \multirow{2}{*}{\multicolumn{2}{|c|}{11}} & $\leq 100$ units & 5.00 & \multirow{2}{*}{140} \\
\hline & & $>100$ units & 8.05 & \\
\hline & 12 & For all units & 12.00 & 690 \\
\hline
\end{tabular}

Actual tariff rates fixed by TNEB has two components $X_{n}$ and $I_{n}$. Where $X_{n}$ is actual energy cost per unit and $I_{n}$ is actual fixed cost for two months. For consumer category $1 X_{n}$ and $I_{n}$ are based on NUC. If NUC $\geq 0$ and $\leq 200$ then $X_{n}$ is Rs 2.50 and $I_{n}$ is Rs 30 . If NUC $\geq 201$ and $\leq 500$ then for first 200 units consumption $X_{n}$ is Rs 2.50 and $I_{n}$ is Rs 40 and for 201 to 500 units consumption $X_{n}$ is Rs 3.0 and $I_{n}$ is Rs 40. If NUC > 500 then $I_{n}$ is Rs 50, for first 100 units consumption $X_{n}$ is Rs 2.50 , for 101 to 200 units consumption $X_{n}$ is Rs 3.50 , for 201 to 500 units consumption $X_{n}$ is Rs 4.60 , for greater than 500 units consumption $X_{n}$ is Rs 6.60. For consumer category $2,3,4,5$, and $6 I_{n}$ is Rs 120 and $X_{n}$ is Rs 4.60, Rs 6.35, Rs 5.75, Rs 7.50 and Rs 5.75. For consumer category $8 I_{n}$ is Rs 120 and $X_{n}$ is Rs 5.20 if NUC $<500$ else $X_{n}$ is Rs 5.75. For consumer category $9 X_{n}$ is Rs 6.35 and $I_{n}$ is Rs 70 . For consumer category $10 X_{n}$ is Rs 3.22 and $I_{n}$ is Rs 0 . For consumer category $11 I_{n}$ is Rs 140 and $X_{n}$ is Rs 5.00 if NUC $<100$ else $X_{n}$ is Rs 8.05. For consumer category $12 X_{n}$ is Rs 12 and $I_{n}$ is Rs 690 .

Table 3: Subsidized tariff rates

\begin{tabular}{|c|c|c|c|c|}
\hline \multicolumn{2}{|c|}{$\begin{array}{l}\text { Consumer } \\
\text { Category }\end{array}$} & NUC & $\begin{array}{l}\text { Subsidized Ener- } \\
\text { gy Cost }\left(\mathrm{Y}_{\mathrm{n}}\right) \\
(\mathrm{Rs} / \text { Unit })\end{array}$ & $\begin{array}{l}\text { Subsidized } \\
\text { Fixed } \\
\text { Cost }\left(\mathrm{J}_{\mathrm{n}}\right)\end{array}$ \\
\hline \multirow{12}{*}{1} & \multirow{3}{*}{ A } & \multicolumn{3}{|c|}{$(\mathrm{NUC} \geq 0$ and $\mathrm{NUC} \leq 200)$} \\
\hline & & $0-100$ units & 0 & 0 \\
\hline & & $101-200$ units & 1.50 & 20 \\
\hline & \multirow{4}{*}{ B } & $(\mathrm{NL}$ & 201 and NUC $\leq$ & \\
\hline & & $0-100$ units & 0 & \multirow{3}{*}{30} \\
\hline & & $101-200$ units & 2.00 & \\
\hline & & $201-500$ units & 3.00 & \\
\hline & \multirow{5}{*}{$\mathrm{C}$} & & $(\mathrm{NUC}>500)$ & \\
\hline & & $0-100$ units & 0 & \multirow{4}{*}{50} \\
\hline & & $101-200$ units & 3.50 & \\
\hline & & $201-500$ units & 4.60 & \\
\hline & & $>500$ units & 6.60 & \\
\hline 2 & & \multirow{5}{*}{ For all units } & 4.60 & 120 \\
\hline 3 & & & 6.35 & 120 \\
\hline 4 & & & 5.75 & 120 \\
\hline 5 & & & 7.50 & 120 \\
\hline 6 & & & 2.85 & 120 \\
\hline \multirow{2}{*}{7} & & $<500$ units & 4.00 & \multirow{2}{*}{40} \\
\hline & & $>500$ units & 4.60 & \\
\hline \multirow{5}{*}{8} & A & $\leq 500$ units & 0 & 0 \\
\hline & $\mathrm{B}$ & 501-750 units & 0 & 0 \\
\hline & $\mathrm{C}$ & $751-1000$ units & 2.30 & 70 \\
\hline & $\mathrm{D}$ & $1001-1500$ units & 3.45 & 70 \\
\hline & $\mathrm{E}$ & $>1500$ units & 4.60 & 70 \\
\hline 9 & \multirow{2}{*}{\multicolumn{2}{|c|}{ For all units }} & 6.35 & 70 \\
\hline 10 & & & 0 & 0 \\
\hline \multirow{2}{*}{11} & & $\leq 100$ units & 5.00 & \multirow{2}{*}{140} \\
\hline & & $>100$ units & 8.05 & \\
\hline & & 12 & 12.00 & 690 \\
\hline
\end{tabular}

Subsidized tariff rates fixed by Tamilnadu government have two components $Y_{n}$ and $J_{n}$. Where $Y_{n}$ is subsidized energy cost per unit and $\mathrm{J}_{\mathrm{n}}$ is subsidized fixed cost for two months. For consumer category 1 , if NUC $\geq 0$ and $\leq 200$ then for first 100 units consumption $Y_{n}$ and $J_{n}$ is Rs 0.0 and for 101 to 200 units consumption 
$Y_{n}$ is Rs 1.50 and $J_{n}$ is Rs 20. For consumer category 2, 3, 4, 5, 6, $7,9,11$ and $12 X_{n}$ is same as $Y_{n}$ and $I_{n}$ is same as $J_{n}$. For consumer category 8, if NUC $\leq 750$ then $Y_{n}$ and $J_{n}$ is Rs 0.0 else $J_{n}$ is Rs 70 , for 751 to 1000 units consumption $Y_{n}$ is Rs 2.30, for 1001 to 1500 units consumption $Y_{n}$ is Rs 3.35, if NUC $>1500$ then $Y_{n}$ is Rs 4.60. For consumer category $10 Y_{n}$ and $J_{n}$ is Rs 0.0 for all units.

\section{Experiments and Results}

Figure 2 illustrates prototype for smart energy meter and the primary components in the prototype includes: energy meter, intel edison board with wifi wireless connectivity, and LCD keypad. Keypad is used in selecting consumer's category. One end of energy meter is connected with $230 \mathrm{v}$ AC input and other end with load. Intel Edison board is connected with energy meter to access NUC.

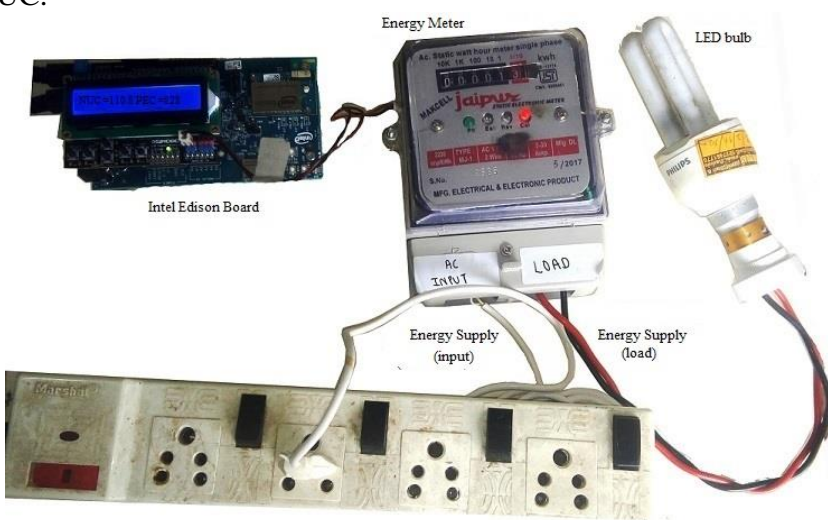

Fig. 2: Smart Energy Meter Prototype

Based on NUC the CEC, SA and PEC can be computed as follows.

$\mathrm{CEC}=\left(\mathrm{NUC} * \mathrm{X}_{\mathrm{n}}\right)+\mathrm{I}_{\mathrm{n}}$

(1)

$\mathrm{PEC}=\left(\mathrm{NUC} * \mathrm{Y}_{\mathrm{n}}\right)+\mathrm{J}_{\mathrm{n}}$

(2)

\section{$\mathrm{SA}=\mathrm{CEC}-\mathrm{PEC}$}

(3)

Where CEC is consumer energy cost, PEC is payable energy cost, and SA is subsidy amount. $X_{n}$ is actual energy cost, $n$ is consumer category, where $\mathrm{n}=1$ to $12, \mathrm{I}_{\mathrm{n}}$ is actual fixed cost for two months for consumer category $\mathrm{n}, \mathrm{Y}_{\mathrm{n}}$ is subsidized energy cost per unit for consumer category $n, J_{n}$ is subsidized fixed cost for 2 months for consumer category $n$. Values for $X_{n}, I n, Y_{n}$, and $J_{n}$ for each consumer category can be referred in table 2 and table 3 . Experiments are conducted using three scenarios described as follows.

Scenario 1: Energy is supplied to 10 watts LED bulb through the smart energy meter. Experiment is conducted by running 10 watts LED bulb for 8 hours (from 9 to 16 hours).

Scenario 2: Energy is supplied a class room through the smart energy meter for 8 hours (from 9 to 16 hours). The class includes 4 numbers of 40 watts tube lights and 4 numbers of 75 watts ceiling fans. Experiments are conducted by running 4 numbers of tube lights and 4 numbers of ceiling fans for 8 hours (from 9 to 16 hours).

Scenario 3: Energy is supplied a class room through the smart energy meter for 30 days. 8 hours daily (from 9 to 16 hours). The class includes 4 numbers of 40 watts tube lights and 4 numbers of 75 watts ceiling fans. Experiments are conducted by running 4 numbers of tube lights and 4 numbers of ceiling fans for 8 hours (from 9 to 18 hours).

Table 4: Results of Scenario 1.2 and 3

\begin{tabular}{|c|c|c|c|c|}
\hline Scenario & NUC & CEC & PEC & SA \\
\hline 1 & 0.08 & 0.6 & 0.6 & 0 \\
\hline 2 & 3.68 & 27.6 & 27.6 & 0 \\
\hline 3 & 110.4 & 828 & 828 & 0 \\
\hline
\end{tabular}

CEC, SA, and PEC for scenario 1, 2, and 3 are computed using tariff rate of consumer category 5 . Values for $X_{n}, I_{n}, Y_{n}$, and $J_{n}$ for consumer category 5 can be referred in table 2 and table 3 . For scenario 1 and 2, let $I_{n}$ and $J_{n}$ value is zero. Table 4 shows the CEC, PEC, and SA for scenario 1, 2, and 3. In scenario 1, NUC is 0.08, CEC is Rs 0.6, SA is zero, and PEC is Rs 0.6. In scenario 2, NUC is 3.68, CEC is Rs 27.6, SA is zero, and PEC is Rs 27.6. In scenario 3, NUC is 110.4, CEC is Rs 828 , SA is zero, and PEC is Rs 828 . Results in table 4 shows the proposed smart energy meter is effective in computing energy cost based on consumer category. Experiments are conducted using test cases in the range of 50 to 400 units and the results are given in table 5. Results in table 5 shows the PEC is equal to CEC for consumer category 2, 3, 4, 5, 7 , 8,11 and 12 . For consumer category $1,6,8$ and 10 PEC is less then CEC. In consumer category 1, SA increases up to 200units. Rs. 350 is the maximum subsidy amount received by consumer category 1 at 200 unit's consumption. Above 200 units consumption SA decreases. For 300 units to 500 unit's consumption, SA is Rs 310. For consumption above 600 units SA is Rs 250. Consumer category 6 enjoys maximum subsidy benefits. In consumer category 8 , for 50 units to 750 units' consumption SA is $100 \%$ above 1500 units' consumption SA is $20 \%$. Consumer category 10 in $100 \%$ subsidized.

Table 5: Summary of CEC, SA, and PEC for all categories of consumers

\begin{tabular}{|c|c|c|c|c|c|c|}
\hline \multirow{2}{*}{$\begin{array}{l}\text { Consumer } \\
\text { Category }\end{array}$} & & \multicolumn{5}{|c|}{ Test Cases (in Units) } \\
\hline & & 50 & 100 & 200 & 300 & 400 \\
\hline \multirow[t]{3}{*}{ 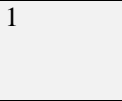 } & CEC & 155 & 280 & 530 & 840 & 1140 \\
\hline & PEC & 0 & 0 & 170 & 530 & 830 \\
\hline & SA & 155 & 280 & 360 & 310 & 310 \\
\hline \multirow[t]{3}{*}{2} & CEC & 350 & 580 & 1040 & 1500 & 1960 \\
\hline & PEC & 50 & 580 & 1040 & 1500 & 1960 \\
\hline & SA & 0 & 0 & 0 & 0 & 0 \\
\hline \multirow[t]{3}{*}{3} & CEC & 43.5 & 755 & 1390 & 2025 & 2660 \\
\hline & PEC & 437.5 & 755 & 1390 & 2025 & 2660 \\
\hline & SA & 0 & 0 & 0 & 0 & 0 \\
\hline \multirow[t]{3}{*}{4} & CEC & 407.5 & 695 & 1270 & 1845 & 2420 \\
\hline & PEC & 407.5 & 695 & 1270 & 1845 & 2420 \\
\hline & SA & 0 & 0 & 0 & 0 & 0 \\
\hline \multirow[t]{3}{*}{5} & CEC & 495 & 870 & 1620 & 2370 & 3120 \\
\hline & PEC & 495 & 870 & 1620 & 2370 & 3120 \\
\hline & SA & 0 & 0 & 0 & 0 & 0 \\
\hline \multirow[t]{3}{*}{6} & CEC & 407.5 & 695 & 1270 & 1845 & 2420 \\
\hline & PEC & 262.5 & 405 & 690 & 975 & 1260 \\
\hline & SA & 145.0 & 290 & 580 & 870 & 1160 \\
\hline \multirow[t]{3}{*}{7} & CEC & 240 & 440 & 840 & 1240 & 1640 \\
\hline & PEC & 240 & 440 & 840 & 1240 & 1640 \\
\hline & SA & 0 & 0 & 0 & 0 & 0 \\
\hline \multirow[t]{3}{*}{8} & CEC & 380 & 640 & 1160 & 1680 & 2200 \\
\hline & PEC & 0 & 0 & 0 & 0 & 0 \\
\hline & SA & 380 & 640 & 1160 & 1680 & 2200 \\
\hline \multirow[t]{3}{*}{9} & CEC & 387.5 & 705 & 1340 & 1975 & 2610 \\
\hline & PEC & 387.5 & 705 & 1340 & 1975 & 2610 \\
\hline & SA & 0 & 0 & 0 & 0 & 0 \\
\hline \multirow[t]{3}{*}{10} & CEC & 161 & 322 & 644 & 966 & 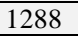 \\
\hline & PEC & 0 & 0 & 0 & 0 & 0 \\
\hline & SA & 161 & 322 & 644 & 966 & 1288 \\
\hline \multirow[t]{3}{*}{11} & CEC & 390 & 640 & 1750 & 2555 & 3360 \\
\hline & PEC & 390 & 640 & 1750 & 2555 & 3360 \\
\hline & SA & 0 & 0 & 0 & 0 & 0 \\
\hline \multirow[t]{3}{*}{12} & CEC & 1290 & 1890 & 3090 & 4290 & 5490 \\
\hline & PEC & 1290 & 1890 & 3090 & 4290 & 5490 \\
\hline & SA & 0 & 0 & 0 & 0 & 0 \\
\hline
\end{tabular}




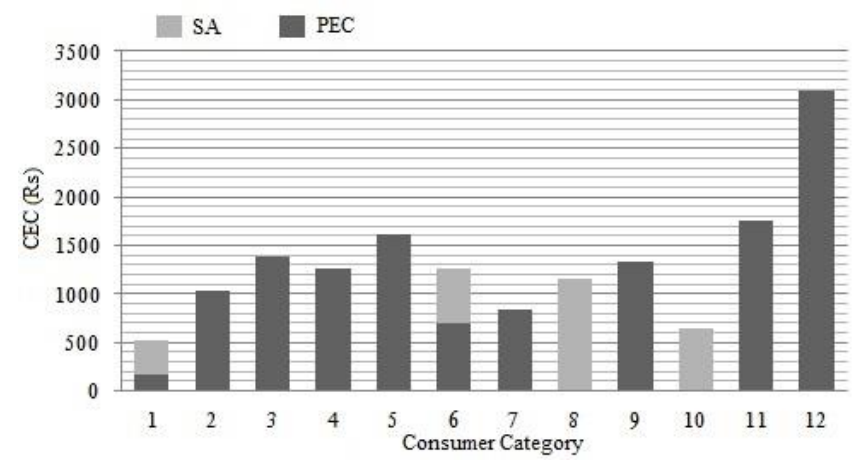

Fig. 3: Energy Cost for consumer category 1 to 12 for 200 unit's consumption

Figure 3 shows the energy costs of consumer category 1 to 12 for 200 unit's consumption. Results shows consumer category 8 and 10 received more subsidiary benefits followed by consumer category 6 and 1 . Energy cost is high for consumer category 12 followed by consumer category $11,5,3,9,4,2$, and 7 . Similar results are reported for the other test cases in table 5 .

\section{Conclusion}

Proposed a smart energy meter for computing energy cost based on consumer category and tariff rate. Experiments are conducted using consumers category and tariff rates of TNEB. Subsidy provided by government to the consumers is taken into consideration in computing energy cost. Proto type is experimented in various scenarios and evaluated using test cases in the range of 50 to 1700 units. CEC, PEC, SA are computed for all categories of consumers using test cases. Results show proposed smart energy meter is effective in computing CEC, SA, and PEC based on consumers category and tariff rates.

\section{References}

[1] Ashna, K., and George, S.N., "GSM based automatic energy meter reading system with instant billing", International MutliConference on Automation, Computing, Communication, Control and Compressed Sensing, pp. 65-72, 2013.

[2] Darshan Iyer, N., and Radha Krishna Rao, K. A., "IoT Based Electricity Energy Meter Reading, Theft Detection and Disconnection using PLC modem and Power optimization", International Journal of Advanced Research in Electrical Electronics and Instrumentation Engineering, vol. 4, issue 7, pp. 6482-6491, 2015.

[3] Dinesh Prasanth, M.K., "Live Energy Meter Reading and Billing System through GPRS", International Journal of Engineering Research \& Technology, Vol. 4, issue 5, pp. 255-299, 2014.

[4] Gobinath, S.,Gunasundari, N., and Gowthami, P., "Internet of Things (IOT) Based Energy Meter", International Research Journal of Engineering and Technology, Vol. 3, issue 4, pp. 1266-1269, 2016.

[5] Karthikeyan, S., and Bhuvaneswari, P.T.V., "IoT based real-time residential energy meter monitoring system", Trends in Industrial Measurement and Automation (TIMA), pp. 1-7, 2017.

[6] Maity, T., and Das, P.S., "Intelligent Online Measurement and Management of Energy Meter Data through Advanced Wireless Network", 2011 International Conference on Devices and Communications (ICDeCom), pp. 1-4, 2011.

[7] Preethi, V., and Harish, v., "Design and implementation of smart energy meter", 2016 International Conference on Inventive Computation Technologies (ICICT), pp. 1-5, 2016.

[8] Primicanta, A.H., Mohd Yunus Nayan., and Awan, M., "ZigBeeGSM based Automatic Meter Reading system", 2010 International Conference on Intelligent and Advanced Systems, pp. 1-5, 2010.

[9] Rashmi, M.N., and Mahadevaswamy, "IOT based Energy Meter Monitoring using ARM Cortex M4 with Android Application", International Journal of Computer Applications, vol. 150, no. 1, pp. 22-27, 2016.

[10] Rawat, N., Rana, S., Yadav, B.,and Yadav,.N., "A review paper on automatic energy meter reading system", 3rd International Confer- ence on Computing for Sustainable Global Development (INDIACom, pp. 3254-3257, 2016.

[11] TNEB Consumer Categories and Tariff Rates. (Order No: T.P.No.1 of 2017 DT: 11.08.2017). https://www.tangedco.gov.in/ linkpdf/ ONE_PAGE_STATEMENT.pdf.

[12] G. Ramprabu, S. Nagarajan, "Design and Analysis of Novel Modified Cross Layer Controller for WMSN", Indian Journal of Science and Technology, Vol 8(5), March 2015, pp.438-444. 